
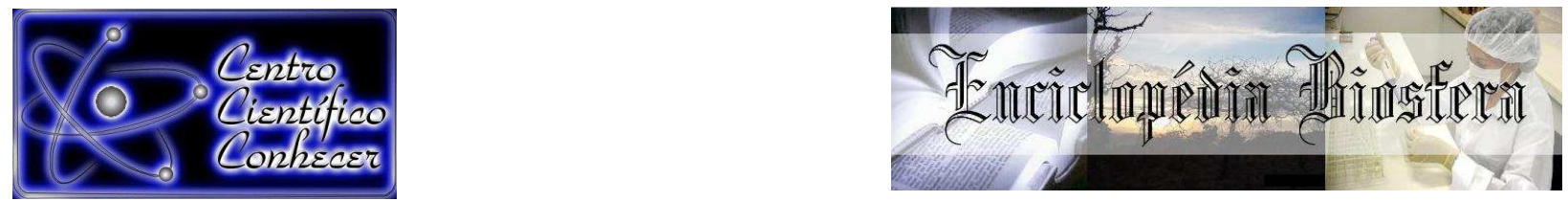

\title{
LEVANTAMENTO BIBLIOGRÁFICO: UM ESTUDO SOBRE AS QUEIMADAS NO CERRADO BRASILEIRO NO PERÍODO DE 2010 A 2016
}

$\underline{\text { Laura de Fátima Costa da Silva }}{ }^{1}$, Daniel Silas Veras $^{2}$, Jéssica Oliveira Chaves ${ }^{3}$

1 Graduada em Licenciatura em Ciências Biológicas- Instituto Federal de Educação, Ciência e Tecnologia do Maranhão - IFMA Campus Caxias

(lauracosta.silva@outlook.com)

2 Professor Mestre - Instituto Federal de Educação, Ciência e Tecnologia do

Maranhão - IFMA Campus Caxias (daniel.veras@ifma.edu.br)

3 Estudante de Pós-Graduação- Instituto Federal de Educação, Ciência e

Tecnologia do Maranhão - IFMA Campus Caxias (jessica.chaves461@gmail.com)

Recebido em: 02/10/2017 - Aprovado em: 21/11/2017 - Publicado em: 05/12/2017

DOI: 10.18677/EnciBio 2017B87

\begin{abstract}
RESUMO
O presente estudo investigativo buscou analisar as causas e consequências das queimadas para o Cerrado brasileiro, haja vista, a busca pelo controle das queimadas, o qual é fator preponderante para a preservação e minimização dos impactos dessa vegetação. Realizou-se um estudo sobre as queimadas no Cerrado brasileiro no período de 2010 a 2016, com intuito de averiguar as consequências das queimadas para a biodiversidade existente e sociedade em geral. A pesquisa foi realizada através de estudo bibliográfico em trabalhos de publicações entre os anos de 2010 a 2016 e sites oficiais. Após a análise e discussão dos dados, encontrou-se que as principais consequências das queimadas no Cerrado brasileiro são: aumento do aquecimento global; redução da mata nativa existente; desflorestamento e perda da biodiversidade; poluição atmosférica; prejuízos econômicos e sociais; mudança climática do país (aumento da temperatura em determinadas regiões); aceleração do processo de desertificação. Conclui-se assim, que o Cerrado brasileiro é o bioma no qual ocorre o maior número de incêndios anualmente e que essas queimadas trazem diversos prejuízos socioambientais.
\end{abstract}

PALAVRAS-CHAVE: Biodiversidade, Incêndios, Impactos, Savana.

\section{BIBLIOGRAPHICAL SURVEY: A STUDY ON BURNED IN BRAZILIAN CLOSURE FOR THE PERIOD FROM 2010 TO 2016}

\begin{abstract}
This research aimed to analyze the causes and consequences of the burnings for the Brazilian Savana, given the search for the control of the burning, which is a preponderant factor for the preservation and minimization of the impacts of this vegetation. A survey was carried out on burnings in the Brazilian Savana between 2010 and 2016, in order to investigate the consequences of burning to existing biodiversity and society. The research was carried out through a bibliographic study
\end{abstract}


in works of publications between the years 2010 to 2016 and official sites. After analyzing and discussing the data, it was found that the main consequences of burning in Brazil are: increased global warming; Reduction of existing native forest; Deforestation and loss of biodiversity; atmospheric pollution; Economic and social losses; Climate change in the country (temperature rise in certain regions); Acceleration of the desertification process. It can be concluded that the Brazilian Savana is the biome in which the highest number of fires occur annually and that these fires bring several socio-environmental damages.

KEYWORDS: Biodiversity, Burned, Impacts, Savana.

\section{INTRODUÇÃO}

A vegetação tem um papel de extrema importância na conservação da existência da vida, pois, esta é um importante componente da biótica, sendo, determinante para a existência ou não de hábitats (ARAÚJO, 2016). Dentro desse contexto se insere a vegetação brasileira que apresenta diferentes e ricos biomas, e atua como agente conservador da existência das espécies, servindo de estudos para as mais diversas áreas do conhecimento.

É entendido por bioma, o espaço geográfico formado por todos os seres de uma determinada região. Dentro desse ambiente, insere-se o bioma brasileiro possuidor de uma gigantesca riqueza fisionômica e florística, formando uma região com muitas peculiaridades e diversidade fisionomicamente (SILVEIRA, 2014).

Um desses biomas é o Cerrado, segundo maior bioma do Brasil, ocupando $22 \%$ do território nacional. Assume papel importante na conservação da grandiosa diversidade biológica existente, sendo considerado a níveis mundiais um verdadeiro hotspot (lugares que apresentam uma grande riqueza natural e uma elevada biodiversidade) de diversidade biológica (PEREIRA; VENTUROLI, 2010).

O Cerrado brasileiro é considerado como a savana mais rica em biodiversidade do mundo, apresentando uma imensa variedade de espécies. Além dos aspectos ambientais, este tipo de vegetação tem uma majestosa importância social, pois muitas comunidades locais sobrevivem dos recursos naturais extraídos desse bioma (BORGES, 2013).

A riqueza do bioma brasileiro tem sido ameaçada principalmente pela ação humana e em específico, o Cerrado que apresenta um processo de devastação bastante acelerado em relação aos últimos anos, sendo consequência do crescimento das cidades, expansão de fronteiras agrícolas, queimadas e entre outros fatores que tem causado o desaparecimento em proporção do ecossistema (BARROS; ALMEIDA, 2013).

Um dos fatores que é salutar um estudo aprofundado de tamanha devastação, diz respeito às extensas queimadas no Cerrado brasileiro. Somos sabedores que o fogo é um fator de perturbação aos domínios fitogeográficos do Cerrado, que geralmente determina a estrutura da vegetação e sua composição, ou seja, a sua existência (MARQUI, 2011). As formas fisionômicas mais comuns do cerrado caracterizam-se por possuir um estrato rasteiro bastante desenvolvido, constituído principalmente por gramíneas e um estrato lenhoso não muito denso, onde as copas das árvores não formam um dossel contínuo.

A necessidade em expor as reais condições da vegetação brasileira, em específicos as do Cerrado, que atualmente se apresenta como bioma ameaçado pelo homem devido suas ações de degradação da vegetação existente, com o uso 
da queimada em todo o cerrado, tornam-se preocupante. Pois, é a falta de controle do homem, que impulsiona a promoção de prejuízos tanto à natureza quanto à sociedade.

Dessa forma, o presente estudo investigativo buscou analisar as causas e consequências das queimadas para o Cerrado brasileiro, haja vista, a busca pelo controle das queimadas, o qual é fator preponderante para a melhoria dessa vegetação. Nesse sentido, fez-se necessário um levantamento sobre as queimadas no Cerrado brasileiro no período de 2010 a 2016, com intuito de averiguar as consequências das queimadas para a biodiversidade existente e sociedade.

Apresentando como objetivo geral: realizar um levantamento sobre as queimadas no cerrado brasileiro no período entre 2010 a 2016, e como específicos: contextualizar o cerrado na vegetação brasileira; realizar um estudo de levantamento sobre as queimadas no cerrado brasileiro; discutir sobre as práticas das queimadas e suas principais consequências ao ecossistema brasileiro.

Deste modo, o presente trabalho torna-se relevante por contribuir para o conhecimento geográfico da realidade da formação vegetacional. Além de expor a necessidade da redução das queimadas não só no cerrado brasileiro, mas, em todos os biomas, com intuito de minimizar as drásticas consequências que o fogo traz para o meio ambiente e a preservação da vida como um todo.

\section{O Cerrado brasileiro}

Os biomas brasileiros têm sido objeto de estudo nas mais variadas áreas do conhecimento, devido à tamanha importância apresentada à conservação da vida no planeta (FERNANDES; PESSÔA, 2011). Dentro desse contexto, apresenta-se o Cerrado brasileiro, segundo maior bioma da América do Sul, com área de 2.036.448 $\mathrm{km}^{2}$, representando $22 \%$ do território brasileiro. Esse bioma abrange 12 estados da federação brasileira, sendo eles: Goiás, Tocantins, Mato Grosso, Mato Grosso do Sul, Minas Gerais, Bahia, Maranhão, Piauí, Rondônia, Paraná, São Paulo e Distrito Federal (BRASIL/MMA, 2015).

O Cerrado faz limite com quatro dos biomas brasileiros: ao norte com a Amazônia; sudoeste com o Pantanal; nordeste com a Caatinga, e, a sudeste com Mata Atlântica. E, essa aproximação com os demais, torna o Cerrado um bioma rico em biodiversidade, pois nele está contido cerca de um terço da biodiversidade brasileira e cerca de $5 \%$ da flora e fauna mundiais (BORGES, 2013), conferindo-Ihe o aspecto ecológico único (BRASIL/MMA, 2014). Seu clima tropical é caracterizado por duas estações: uma chuvosa e outra seca, é nesta segunda estação que há a predominância das queimadas.

O Ministério do Meio Ambiente em seu relatório em 2011 diz que o Cerrado brasileiro é considerado como a savana mais rica do mundo, porém, a mais ameaçada, essa heterogeneidade ambiental, característica existente neste bioma, torna-o um hotspot biológico (BRASIL, 2011). Quanto a flora do Cerrado, Fernandes e Pessoa (2011), informam que a mesma é formada por árvores baixas, arbustos espaçados e gramíneas, apresentando uma rica variedade de espécies, tendo sido catalogada em torno de 11.627 espécies de plantas; cerca de 199 espécies de mamíferos; 837 espécies avifauna; 1200 espécies de peixes; 180 espécies répteis; 150 espécies anfíbios entre outros.

Em confirmação ao listado acima, Barros e Almeida fazem breve relato da biodiversidade existente no cerrado brasileiro, a partir do entendimento da organização World Wildlife Fund (WWF): 
[...] é área de reprodução de 759 espécies de aves e abriga 180 de répteis e 195 de mamíferos. Por situar-se em uma posição central no território brasileiro, oferecendo uma espécie de ponte entre a Amazônia, o Pantanal, a Caatinga e a Mata Atlântica, o Cerrado compartilha animais e plantas com todos esses biomas, sem deixar de abrigar exemplares únicos da biodiversidade brasileira. Somente no Distrito Federal encontram-se 90 espécies de cupins, mil de borboletas e quinhentas de abelhas e vespas. Existe ainda, 4.400 espécies de plantas e 117 de vertebrados seriam endêmicas, englobando, respectivamente, $1,5 \%$ e $0,4 \%$ das espécies conhecidas no mundo (BARROS; ALMEIDA, 2013, p. 10-11).

Além da importância ambiental, o Cerrado possui outros atributos, como a relevância socioeconômica para a comunidade local e até mesmo, para a economia nacional. Portanto, o Cerrado é um bioma estratégico para o Brasil, tanto paro o meio ambiente quanto economicamente falando, pois somos conhecedores da participação efetiva deste na economia nacional (BRASIL, 2014). Ele também ocupa um papel de destaque na economia brasileira, pois abriga uma rica sociobiodiversidade, composta por diversas etnias que desenvolvem seu modo de vida e economia com a utilização dos recursos naturais deste bioma (BRASIL, 2011). Sobre esse argumento, Araújo (2016) faz uma lista da importância do cerrado brasileiro para a comunidade local, asseverando que:

[...]. Muitas populações sobrevivem de seus recursos naturais, incluindo etnias indígenas, quilombolas, geraizeiros, ribeirinhos, babaçueiras, vazanteiros e comunidades quilombolas que, juntas, fazem parte do patrimônio histórico e cultural brasileiro, e detêm um conhecimento tradicional de sua biodiversidade (ARAÚJO, 2016, p. 10).

Quanto a importância econômica do Cerrado brasileiro, Fernandes e Pessoa (2011) dizem que este bioma é responsável pela maior fonte de produção de grãos do Brasil, em especial, a soja, produção de algodão, arroz e milho, pecuária. Já Silveira (2010), indica que esse bioma apresenta um enorme potencial econômico para diversos setores, tais como: madeireiro, alimentar, combustível, ornamental, forrageiro, e medicinal a partir da grande variedade da fauna e flora existente.

Apesar da relevância do Cerrado nos aspectos biológicos, sociais e econômicos do Brasil, ele é bioma que possui a menor área protegida, apenas $8,21 \%$ de seu território é legalmente protegido por unidades de conservação; desse total, $2,85 \%$ são unidades de conservação de proteção integral e $5,36 \%$ de unidades de conservação de uso sustentável, incluindo Reservas Particulares do Patrimônio Natural- RPPNs (0,07\%) (BRASIL, 2016).

\section{As queimadas naturais e antrópicas}

As queimadas são fatores ocorridos em todo território nacional, independente da região ou estação do ano, porém, o aumento dos índices de focos de incêndios é mais evidenciado no período de seca, ou seja, na falta de ocorrência de chuvas. E, essas queimadas ocorrem por diversos fatores, ocorrem de forma natural e/ou antrópicas, porém, é mais evidenciado na utilização do solo para a prática da pecuária, agricultura e carvoaria (PEREIRA et al. 2011).

Cabe destacar que o Cerrado brasileiro é dependente do fogo, tendo em vista, este ser um elemento indispensável para a manutenção da biodiversidade, 
pois esse fenômeno atua como um importante agente ecológico ao influenciar, tanto processos de trocas químicas como biológicas em suas diferentes fitofisionomias (NASCIMENTO, 2001). Segundo o entendimento do Ministério do Meio Ambiente (MMA), os incêndios naturais ocorridos no Cerrado há muito tempo são considerados essenciais no processo evolutivo para as adaptações morfológicas e fisiológicas da vegetação (BRASIL, 2014). Deste modo, as queimadas que ocorrem por fatores naturais são fenômenos de transformação do Cerrado brasileiro.

No entanto, o fogo também pode levar a efeitos negativos as áreas de Cerrado, pois a destruição da vegetação, independentemente do tipo de bioma, pelas queimadas causa problemas sérios para o equilíbrio ambiental, ocasionando uma decomposição do solo e perda do carbono. A queima da matéria orgânica leva ao aumento da temperatura e da emissão de $\mathrm{CO}_{2}$, ocasionando sérios problemas ao meio ambiente e ao indivíduo. Onde há o fogo é frequente pode ocorrer a permanente redução da diversidade em decorrência da simplificação da estrutura da comunidade, tornando a fisionomia gradualmente mais aberta (SILVEIRA, 2010).

Segundo o entendimento de Marqui (2011) as queimadas são mecanismo de distribuição dos gases que poderá atingir as áreas urbanas, misturando-se com a poluição causada pelos homens e aumentando a poluição da região atingida. A fumaça pode se propagar por uma área de 4,5 milhões de quilômetros quadrado.

As queimadas ocorrem geralmente, em períodos secos, com baixos níveis de chuvas, piorando a qualidade do ar. Muitas são as consequências das queimadas, dentre elas podemos destacar: destruição da fauna e flora, aumento das temperaturas, diminuição da qualidade do ar, além dessas consequências, as queimadas ocasionam ao homem problemas de saúde, especialmente os respiratórios (MARQUI, 2011).

\section{Amparo legal}

Segundo entendimento de Barros e Almeida (2013) sob o aspecto legal, a Constituição da República de 1988, em seu artigo 225, destaca que o meio ambiente ecologicamente equilibrado se constitui um direito universal, assim como seu uso comum pelo povo, sendo essencial à sadia qualidade de vida. Por isso, o poder público e a coletividade têm o dever de defendê-lo e preservá-lo para as presentes e futuras gerações. Portanto, os diversos biomas brasileiros merecem proteção, pois devem ser considerados "patrimônio nacional" (BORGES, 2013).

Abaixo foi feito um breve apanhado sobre as principais leis que regulam no âmbito jurídico os mecanismos que asseguram a proteção ambiental, para tal, teve como suporte bibliográficos as obras de: Barros e Almeida (2013); Brasil (2016); Borges (2013); Machado (2015); Fernandes e Pessoa (2011);

$\checkmark$ Lei 4.771 de 1965, conhecido como o Código Florestal Brasileiro, esta lei alterada pela Medida Provisória no 2.166-65, de 2001 e demais regulamentações, (MACHADO, 2015);

$\checkmark$ Em 1979 foi instituída a Lei 6.766 - o parcelamento do solo para fins urbanos será regido por esta Lei, conhecida como Lei do Parcelamento do Solo Urbano (BRASIL, 2016);

$\checkmark$ No ano de 1981 a Lei 6.938, foi constitui a Política e o Sistema Nacional do Meio Ambiente, seus fins e mecanismos de formulação e aplicação, e dá outras providências. Essa Lei institui o Conselho Nacional do Meio Ambiente CONAMA (BRASIL, 2016);

$\checkmark$ A Lei n. 6.902 de 1981 instituiu a Lei da Área de Proteção Ambiental - cria as 
áreas representativas de ecossistemas brasileiros, sendo que $90 \%$ delas devem permanecer intocadas e $10 \%$ podem sofrer alterações para fins científicos, sendo criada aqui a "Estações" (BRASIL, 2016);

$\checkmark$ Lei da Ação Civil Pública foi promulgada em 1985 pela Lei 7.347, que trata da ação civil pública de responsabilidades por danos causados ao meio ambiente, ao consumidor e ao patrimônio artístico, turístico ou paisagístico (BRASIL, 2016);

$\checkmark$ No ano de 1989 foi instituída a Lei dos Agrotóxicos, Lei n. 7.802 - esta regula desde a pesquisa, fabricação dos agrotóxicos, comercialização, aplicação, controle, fiscalização e também o destino da embalagem (BRASIL, 2016);

$\checkmark$ A Lei n. 7.805 de julho de 1989 cria o regime de permissão de lavra garimpeira, extingue o regime de matrícula, ou seja, esta regula a Exploração Mineral, regulamentando as atividades garimpeiras (FERNANDES e PESSOA, 2011);

$\checkmark$ Lei dos recursos hídricos que institui a Política e o Sistema Nacional de Recursos Hídricos, foi criada em 1997 pela Lei 9.433/1997, define a água como recurso natural limitado, dotado de valor econômico (BORGES, 2013);

$\checkmark$ Lei 9.605 de 1998, a Lei dos Crimes Ambientais, reordena a legislação ambiental quanto às infrações e punições (BRASIL, 2016);

$\checkmark$ Lei 9.985 de 2000 - o Sistema Nacional de Unidades de Conservação da Natureza, foi instituído por esta lei. Dentre os seus objetivos está: a conservação de variedades de espécies biológicas e dos recursos genéticos; a preservação e restauração da diversidade de ecossistemas naturais e a promoção do desenvolvimento sustentável a partir dos recursos naturais (BRASIL, 2016);

$\checkmark$ Lei de Gestão de Florestas Públicas criada pela Lei no 11284 de 2006 normatiza o sistema de gestão florestal em áreas públicas e com a criação do órgão regulador (Serviço Florestal Brasileiro) e do Fundo de Desenvolvimento Florestal (FERNANDES; PESSOA, 2011);

$\checkmark$ Lei 11.445 de 2007 - estabeleceu a Política Nacional de Saneamento Básico versa sobre drenagem urbana, abastecimento de água, esgotamento sanitário e resíduos sólidos (BRASIL, 2016);

$\checkmark$ A Lei 11.105/2005, instituiu a Lei de Biossegurança, estabelecendo o sistema de fiscalização das atividades que envolvem organismos modificados geneticamente (BORGES, 2013);

$\checkmark$ Lei de Gestão de Florestas Públicas - Lei o 11.284/2006, estabeleceu o Serviço Florestal Brasileiro, além de criar Fundo de Desenvolvimento Florestal (BRASIL, 2016);

$\checkmark$ Lei 12.305 de 2010 - institui a Política Nacional de Resíduos Sólidos (PNRS) e foi altera a Lei 9.605/1998 - estabelece diretrizes à gestão integrada e ao gerenciamento ambiental adequado dos resíduos sólidos (FERNANDES; PESSOA, 2011);

$\checkmark$ Lei 12.651 de 2012 - definiu o Novo Código Florestal Brasileiro, definindo a proteção da vegetação nativa, obrigando o proprietário manter espaços protegidos de propriedade privada, divididos entre Área de Preservação Permanente (APP) e Reserva Legal (RL) (BARROS; ALMEIDA, 2013). 


\section{MATERIAL E MÉTODOS}

A pesquisa apresenta-se como forma de investigação, com finalidade de buscar respostas às indagações da sociedade por meio de procedimentos científicos. Desta forma, o estudo aqui evidenciado fez uso da pesquisa bibliográfica, onde segundo, Gil (2009), explica que a pesquisa bibliográfica é desenvolvida mediante material já elaborado, principalmente em livros e artigos científicos.

Assim, o estudo em evidência trata de uma pesquisa de revisão de literatura com abordagem quantitativa do tipo exploratório. Este procedimento foi escolhido por possibilitar a síntese e análise do conhecimento científico já produzido sobre o tema "as queimadas no cerrado brasileiro no período de 2010 a 2016".

Para a realização desta pesquisa tomou-se como base os artigos publicados, revistas eletrônicas, sites do ano de 2010 a 2016. Quanto à abordagem do problema, foi utilizada a análise quantitativa, na medida em que este se caracteriza pela utilização de métodos estatísticos, tanto durante a coleta quanto a interpretação dos dados.

Como critério de inclusão, utilizou-se os artigos, monografias, livros em língua vernácula publicadas a partir de 2010 a 2016. Foram utilizados como critérios de exclusão as publicações em línguas estrangeiras. A pesquisa foi realizada no período de maio a dezembro de 2016.

$\mathrm{Na}$ realização do estudo bibliográfico foi adotado trabalhos que nortearam o estudo. Foi realizado um breve apanhado sobre as queimadas no Brasil e adotou-se como referências para o estudo: Araújo , (2016); Borges (2013); Barros (2013); Marqui (2011); Fernandes e Pessôa (2011); Pereira (2011); Brasil (2015); Pereira et al. (2011); Silveira (2010); Machado(2015); Brasil, (2016);; INPE, (2016a); INPE, (2016b);; IBGE, 2015; G1, (2016a); G1, (2016b); Gaspar (2012); Portal do Brasil (2016); Francisco, (2016);

A etapa seguinte consistiu na identificação e localização das fontes, com obtenção do material por busca eletrônica, uma compilação. Posteriormente, procurou-se identificar os trabalhos de pesquisas que contemplassem o tema proposto.

Após a identificação dos estudos, realizou-se uma leitura criteriosa dos títulos, de todas as publicações completas localizadas pela estratégia de busca. A partir da conclusão desse procedimento, elaborou-se uma síntese com os estudos pré-selecionados para a revisão.

Depois de selecionadas as referências, procedeu-se para leitura e organização do tema encontrado nos estudos no decorrer da pesquisa. Analisou-se criteriosamente o conteúdo bibliográfico, no intuito de esclarecer os objetivos formulados para que tivesse uma interpretação e uma análise exata das fontes pesquisadas, realizando a análise da amostra bibliográfica, acompanhada de discussão crítica sobre o resultado encontrado. A última etapa do processo foi à discussão do tema, em que o pesquisador indica os dados mais relevantes para seu estudo.

\section{RESULTADOS E DISCUSSÃO}

No início da pesquisa utilizaram-se uma análise de forma abrangente em relação aos índices de queimadas ocorridas no Brasil de 2010 a 10 de dezembro de 2016, através dos dados coletados do Programa de queimadas do Instituto de Pesquisas Espaciais (INPE), Instituto Brasileiro de Geografia e Estatística (IBGE) e Ministério do Meio Ambiente (MMA). 
Vale lembrar, que os focos de incêndios, segundo o entendimento do IBGE (2015, p. 49), as queimadas e os incêndios florestais são detectados por satélites como focos de calor sobre a superfície terrestre. Dessa forma, esses dados foram selecionados, categorizados e expostos conforme Tabela 1.

TABELA 1. Comparativo em números e percentuais de focos de incêndios no Brasil entre 2010 - 2016.

\begin{tabular}{lcc}
\hline ANO DE OCORRÊNCIA & NÚMERO ABSOLUTO & PERCENTUAL \\
\hline $\mathbf{2 0 1 0}$ & 249.291 & $19,24 \%$ \\
$\mathbf{2 0 1 1}$ & 133.087 & $10,27 \%$ \\
$\mathbf{2 0 1 2}$ & 193.838 & $14,96 \%$ \\
$\mathbf{2 0 1 3}$ & 115.220 & $8,89 \%$ \\
$\mathbf{2 0 1 4}$ & 183.693 & $14,18 \%$ \\
$\mathbf{2 0 1 5}$ & 236.371 & $18,24 \%$ \\
$\mathbf{2 0 1 6}$ & 184.248 & $14,22 \%$ \\
\hline TOTAL & $\mathbf{1 . 2 9 5 . 7 4 8}$ & $\mathbf{1 0 0 , 0 0 \%}$ \\
\hline
\end{tabular}

Fonte: INPE, 2016.

No Brasil de 2010 a 10 de dez/2016 ocorreram 1.295 .748 focos de incêndios. Destes, com maior incidência foi nos anos de 2010 com 249.291 e 2015 236.371. De acordo com Tabela 1 houve oscilação de focos de incêndios no Brasil de 2010 a dez/2016, nos anos de 2011 e 2013 ocorreram uma redução do número de focos de calor em todos os biomas, enquanto que os demais anos esses números aumentaram consideravelmente.

O ano de 2010 foi o período de maior incidência de focos no Brasil, pois ocorreram 244.704 focos segundo o INPE (2016). Em 2015 esses números também foram bastante elevados, com 236.371 focos de incêndios. Em termos percentuais apenas os anos de 2010 e 2015 tiveram $37,59 \%$ do total de focos de incêndios nos últimos 7 anos, ou seja, dos 1.295 .748 focos corridos nesse período, 466.746 focos foram só nos dois anos já mencionados.

O ano de 2016 é o quarto ano com maior incidência de incêndios, pois até o início do mês de dezembro foram detectados 184.248 focos que corresponde a $14,81 \%$ do total em sete anos pesquisados, perdendo apenas para 2010, 2012 e 2015 e isso coloca o Brasil no topo da lista de países com o maior número de queimadas da América Latina. Sobre tal constatação, Gaspar (2012) extraiu do INPE, que o Brasil vem liderando o topo dos países da América Latina com número de queimadas, sendo os meses de junho a novembro, o período mais crítico, pois são os meses em que geralmente ocorrem queimadas em praticamente em todas as regiões do país.

Ainda segundo o autor, a incidência de queimadas e dos incêndios florestais são um dos principais problemas que o Brasil enfrenta. Tal evidência coloca o país como um dos principais poluidores do mundo por emissão de gases estufa no planeta. Diversos são os fatores para tal ocorrência das queimadas segundo Francisco (2016), no qual podemos destacar:

- Fatores naturais - a estação da seca (julho e novembro), aliada à formação de bolsões de calor nas Regiões Norte, Nordeste e Centro-Oeste, favorece a 
ocorrência de queimadas;

- Pecuária extensiva;

- Agricultura mecanizada;

- Incêndios criminosos (intencional).

As principais consequências das queimadas, especialmente, quando ocorrem de forma antrópicas e descontrolada são:

- Aumento do aquecimento global;

- Redução da mata nativa existente;

- Desflorestamento e de perda da biodiversidade;

- Poluição atmosférica;

- Prejuízo econômicos e sociais; regiões);

- Mudança climática do país (aumento da temperatura em determinadas

- Acelera o processo de desertificação;

O IBGE (2015) levanta um questionamento sobre a evidência, discorrendo a frequência da ocorrência de focos de incêndios no país, por ser um indicador do avanço das atividades agropecuárias sobre as áreas nativas. Assim, como também, o uso do fogo durante a colheita, principalmente, em canaviais, além da queima dos resíduos nas plantações de algodão.

Outro fator que deve ser levado em consideração, diz respeito ao longo período de estiagem em algumas regiões brasileiras, como o Cerrado, por exemplo, pois são regiões de clima quente, com aumento considerável na temperatura e baixa umidade relativa do ar, elementos fundamentais a proliferação dos focos de incêndios.

Somos conhecedores que o cerrado brasileiro é o segundo maior bioma do Brasil, só perdendo para a Amazônia. Porém, traz números assustadores quanto a devastação causada pelo fogo, os dois maiores biomas brasileiro são os mais atingidos por queimadas, dentre eles o mais afetado: o cerrado. Seja qualquer um dos fatores de ocorrência, as queimadas trazem como principal consequência a redução e a extinção da flora e a fauna do Cerrado.

De acordo com a Figura 1, extraído do INPE, os pontos vermelhos mostram os focos de incêndios ocorridos no Brasil entre os anos de 2010 a 2016, pela imagem pode-se observar que a maior incidência de incêndios para os anos considerados ocorreu no Cerrado brasileiro: 

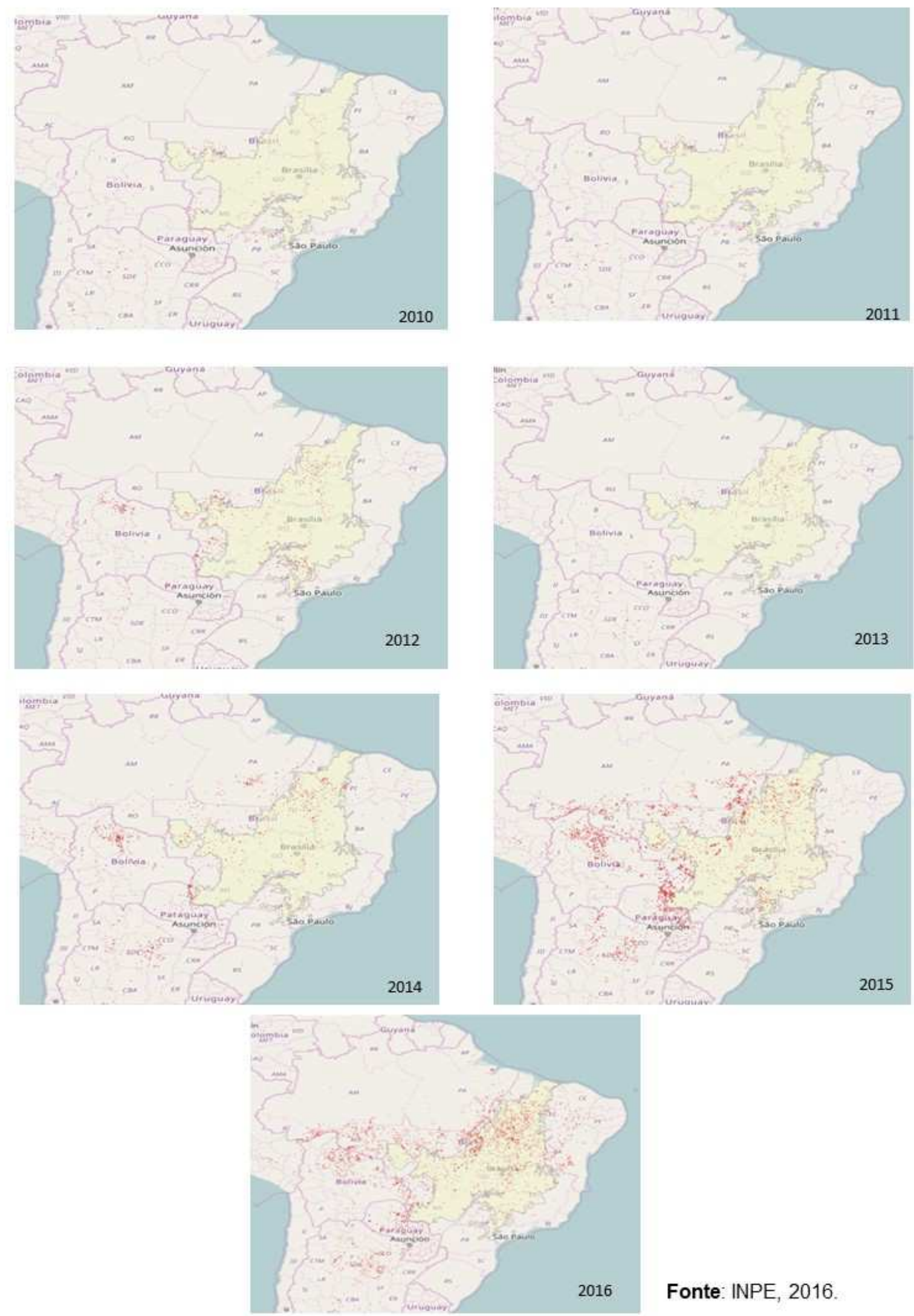

Fonte: INPE, 2016.

FIGURA 1. Mapas dos focos de incêndios no Brasil entre 2010 - 2016. 
De acordo com a Tabela 2, pode-se observar que a maior perda de área em quilômetros quadrados por ocorrência de queimadas é no bioma Cerrado, que acumulou uma perda de 2.625.107 $\mathrm{Km}^{2}$ entre os anos de 2010 - 2016, ou seja, praticamente todo o Cerrado já sofreu uma grande devastação, muitas vezes causada pela ação humana. Durante o período considerado as maiores perdas de áreas ocorreram nos anos de 2015 com $459.064 \mathrm{Km}^{2}$ e $2010 \mathrm{com} 445.111 \mathrm{Km}^{2}$.

TABELA 2. Números de área queimada $\left(\mathrm{Km}^{2}\right)$ por bioma no Brasil entre 2010 2016.

\begin{tabular}{lccccccc}
\hline Ano & Amazônia & Caatinga & Cerrado & $\begin{array}{c}\text { Mata } \\
\text { Atlântica }\end{array}$ & Pampa & Pantanal & $\begin{array}{c}\text { Total } \\
\text { anual }\end{array}$ \\
\hline $\mathbf{2 0 1 0}$ & 140.264 & 102.921 & 445.111 & 44.202 & 676 & 21.933 & $\mathbf{7 5 5 . 1 0 7}$ \\
$\mathbf{2 0 1 1}$ & 75.981 & 97.118 & 291.305 & 60.067 & 944 & 16.628 & $\mathbf{5 4 2 . 0 4 3}$ \\
$\mathbf{2 0 1 2}$ & 97.102 & 152.243 & 441.422 & 44.596 & 2.886 & 22.662 & $\mathbf{7 6 0 . 9 1 1}$ \\
$\mathbf{2 0 1 3}$ & 59.747 & 103.548 & 251.861 & 33.577 & 1.214 & 13.376 & $\mathbf{4 6 3 . 3 2 3}$ \\
$\mathbf{2 0 1 4}$ & 140.110 & 115.096 & 397.296 & 59.702 & 2.416 & 6.022 & $\mathbf{7 2 0 . 6 4 2}$ \\
$\mathbf{2 0 1 5}$ & 281.559 & 196.373 & 459.064 & 71.848 & 5.719 & 17.685 & $\mathbf{1 . 0 3 2 . 2 4 8}$ \\
$\mathbf{2 0 1 6}$ & 158.360 & 64.654 & 339.048 & 102.226 & 7.871 & 18.281 & $\mathbf{6 9 0 . 4 4 0}$ \\
\hline TOTAL & $\mathbf{9 5 3 . 1 2 3}$ & $\mathbf{8 3 1 . 9 5 3}$ & $\mathbf{2 . 6 2 5 . 1 0 7}$ & $\mathbf{4 1 6 . 2 1 8}$ & $\mathbf{2 1 . 7 2 6}$ & $\mathbf{1 1 6 . 5 8 7}$ & $\mathbf{4 . 9 6 4 . 7 1 4}$ \\
\hline
\end{tabular}

Fonte: INPE, 2016.

No entendimento de Francisco (2016) a situação acima ocorre devido alguns fatores como:

- Queimadas para abertura de campos para criação da pecuária extensiva: este tipo de estratégia é realizado principalmente por gerar custos baixos no preparo do solo ao pecuarista; cultivo da soja;

- Agricultura mecanizada no cultivo de milho e algodão, e, principalmente

- Tocos de cigarros jogados na mata - que em altas temperaturas e tempo seco propagam do fogo rapidamente na vegetação existente;

- Causas naturais - biomassa seca, baixa umidade do ar e temperaturas muito elevadas favorece o surgimento de focos de incêndios, além do atrito entre rochas podem acabar desencadeando a queimada.

As queimadas no cerrado brasileiro apresentam duas vertentes: a primeira danosa ao meio ambiente e a outra quando ocorrida por fatores naturais e de forma controlada é benéfica. Francisco (2016) faz um resumo dos benefícios trazido pelas queimadas no cerrado brasileiro:

- Contribui para germinação das sementes, que necessitam de um choque térmico para que aconteça a quebra de sua dormência vegetativa;

- As queimadas contribuem também para a ciclagem de nutrientes do solo;

- As formas retorcidas das árvores, fazendo com que suas gemas de rebrota ocorram lateralmente.

As cascas espessas dos troncos funcionam como um mecanismo de defesa às queimadas. Dessa forma, obtendo a recuperação do cerrado ocorrido de forma rápida, onde a rebrota ocorre em curto prazo de tempo, e, este traz consigo diversos animais atrás das novas folhagens. Já outros seguem as queimadas atrás de comidas, como: anus, carcarás e seriemas, que seguem as queimadas e alimentamENCICLOPÉDIA BIOSFERA, Centro Científico Conhecer - Goiânia, v.14 n.26; p.1040 2017 
se de insetos e répteis atingidos pelo fogo.

A outra vertente do fogo no cerrado é bem negativa, pois esta traz consequências severas ao meio ambiente e ao próprio homem, principal causador das queimadas, das quais destacamos:

- Degradação do ambiente;

- Esgotamento das terras;

- Erosão;

- Perda da biodiversidade do cerrado.

O Cerrado brasileiro corresponde, em percentuais de queimadas, $69 \%$ de todos os biomas existentes no Brasil, ou seja, mais da metade dos focos de incêndios ocorrido no país concentram-se nesse bioma. Na tabela 3, pode-se observar que o Mato Grosso é o estado com maior número de ocorrência de queimadas com 197.082 casos correspondendo a $22 \%$ do total, seguindo do estado do Maranhão com 168.155 dando um percentual de 18,81\%. Já o terceiro colocado no ranking das queimadas no cerrado é o estado do Tocantins com 111.458 casos correspondendo $12,47 \%$.

TABELA 3. Comparação do total de focos de incêndios ativos detectados pelo satélite por estados que apresentam o bioma Cerrado brasileiro, no período de 2010 - 2016.

\begin{tabular}{lcc}
\hline \multicolumn{1}{c}{ ESTADOS } & \multicolumn{2}{c}{ TOTAL } \\
\hline Goiás & No de Focos & $\%$ \\
Distrito Federal & 44.454 & $4,97 \%$ \\
Bahia & 1.715 & $0,19 \%$ \\
Maranhão & 85.691 & $9,59 \%$ \\
Mato Grosso & 168.155 & $18,81 \%$ \\
Mato Grosso do Sul & 197.082 & $22,05 \%$ \\
Minas Gerais & 35.094 & $3,93 \%$ \\
Paraná & 68.864 & $7,70 \%$ \\
Piauí & 16.549 & $1,85 \%$ \\
Rondônia & 81.614 & $9,13 \%$ \\
São Paulo & 60.207 & $6,74 \%$ \\
Tocantins & 22.882 & $2,56 \%$ \\
\hline TOTAL & 111.458 & $12,47 \%$ \\
\hline
\end{tabular}

Fonte: INPE, 2016.

A tabela 4 confirma todos os índices anteriormente discutidos, quando mostra a ocorrência de focos de incêndios no cerrado por ano e estado. Do total dos focos de incêndios referenciado acima, de 1.295.748 ocorridos no Brasil em 7 anos, 893.765 ocorrem só no cerrado. E destes, os maiores índices ocorreram nos estados do Mato Grosso, Maranhão e Tocantins. 
TABELA 4. Comparação do total de focos de incêndios ativos detectados pelo satélite no cerrado brasileiro por ano de ocorrência, no período de $2010-2016$.

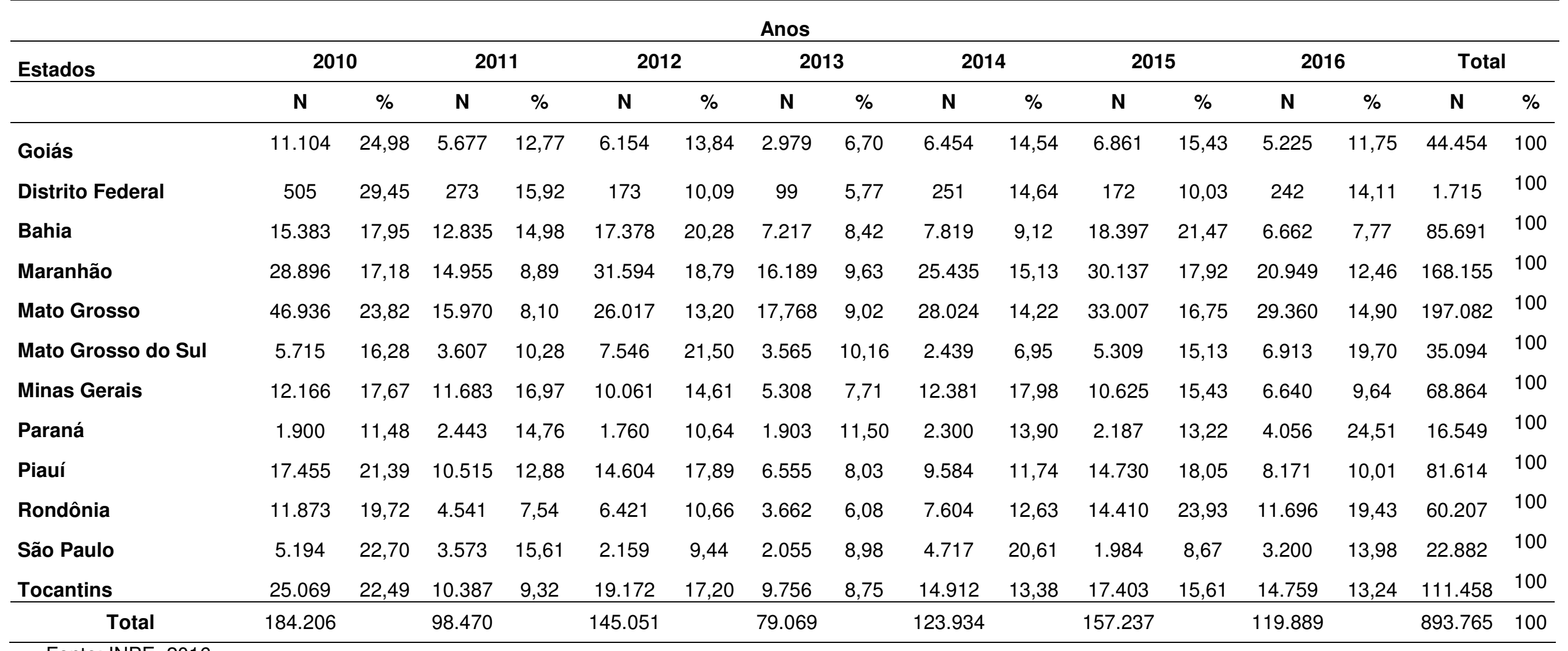

Fonte: INPE, 2016. 
Os dois estados mais atingidos correspondem juntos (Mato Grosso e Maranhão), a $41 \%$ do percentual de ocorrência de queimadas no cerrado brasileiro com 365.237 de focos. Desses, 189.285 foram detectados apenas no ano de 2010, 2105 e 2016, correspondendo $52 \%$ de todos os focos ocorridos nos dois estados. No Tocantins os maiores focos de incêndios ocorreram no ano de 2010 com 25.069 casos. Já do ano de 2016 em relação ao ano de 2015, ocorreu uma ligeira queda nas ocorrências, com diferença de 28.927 casos entre os estados de maiores incidências (Mato Grosso e Maranhão).

A maior quantidade de focos de incêndios ocorreu no ano de 2010 e 2015 no Mato Grosso com 79.943 casos. No ano de 2016 até os dez primeiros dias do mês de dezembro, foram detectados 29.360 focos de incêndios. Já no estado do Maranhão nos anos de 2010 e 2015 tiveram 59.033 focos, e 20.949 focos até dia 10 de dezembro de 2016.

Segundo o INPE (2016b), o Maranhão é o terceiro estado brasileiro com maior número de queimadas no Brasil. Nesse estado o ponto crítico de ocorrência em 2016 se deu nos meses de outubro e novembro com 9.333 focos de incêndios, correspondendo $44,55 \%$ de todos os focos ocorridos no ano.

Ainda sobre esses alarmantes índices, o Portal Globo (G1, 2016a) relatou que em dezembro de 2015, 3.706 incêndios foram registrados em todo o território maranhense, sendo o mais crítico dos últimos 19 anos. A situação no ano de 2016 no estado do Maranhão foi tão crítica, que o governador do estado decretou situação de emergência em todo o estado, com a finalidade de agilizar os procedimentos de combate às chamas e facilitar a liberação de recursos (G1, 2016b).

Dentro do estado o maior número de focos ocorreu no leste maranhense, deixando a região em completa situação de risco. Segundo os órgãos competentes esses focos ocorreram devido o prolongamento da estiagem na região. A situação ocorrida trouxe além dos danos ao meio ambiente, riscos de prejuízos econômicos tanto ao setor público quanto ao privado, danos sociais com diversas famílias desabrigadas, e, principalmente, ambientais com uma imensa área devastada (G1, 2016a).

Além dos danos à biodiversidade, da exposição do solo à ação das intempéries (intensificando processos erosivos) e do comprometimento dos recursos hídricos, há também a geração e a transferência para a atmosfera de grandes quantidades de gases de efeito estufa, especialmente $\mathrm{CO}_{2}$ (IBGE, 2015, p. 49). A figura 2 demonstra a devastação trazida pelas queimadas, na cidade de Caxias, no estado do Maranhão. 

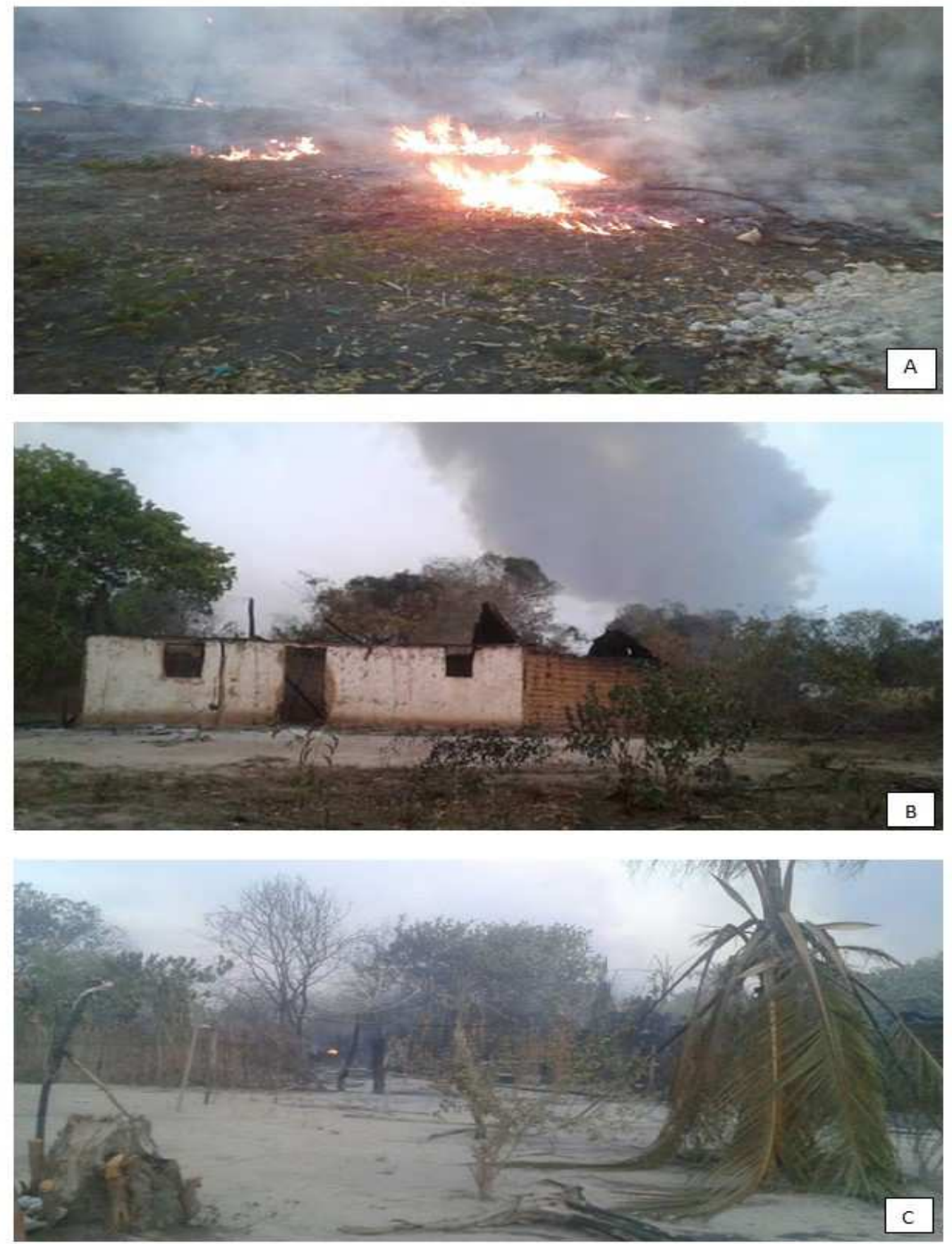

Fonte: Pesquisa de campo, 2016

FIGURA 2. Queimadas em Caxias, uma das cidades mais atingidas pelas queimadas em 2016: A. Vegetação em chamas; B. Casa Incendiada; $\mathrm{C}$.

Diante do exposto na Figura 2, Gaspar (2012) sugere algumas medidas para minimização dos focos de queimadas no cerrado brasileiro, sendo:

- Realizar queimadas apenas com a autorização do Instituto Brasileiro do Meio Ambiente e dos Recursos Naturais Renováveis (Ibama); 
- Fazer queimadas de maneira controlada;

- Apagar o fogo feito em acampamentos utilizando água, para evitar que a brasa seja levada pelo vento para as matas;

- Não jogar pontas de cigarros acesas próximas de vegetação;

- Evitar utilização de qualquer tipo de fogo em reservas ecológicas ou parques florestais.

\section{CONCLUSÃO}

Após a análise e discussão dos dados sobre as práticas das queimadas e suas principais consequências ao ecossistema brasileiro, encontrou-se as seguintes respostas: o Cerrado brasileiro é a região com maior ocorrência de focos de queimadas do Brasil; as queimadas no cerrado no período compreendido da pesquisa destruíram parte da vegetação de todos os estados que compõem este bioma; o Mato Grosso e Maranhão são os estados do cerrado que mais sofrem com as queimadas no Brasil; as queimadas trazem consigo uma ampla devastação tanto ao meio ambiente, quanto ao homem e a estrutura socioeconômica existente no país.

\section{REFERÊNCIAS}

ARAÚJO, P. Biomas. Ministério do Meio Ambiente. Brasília, DF: MMA, 2016. Disponível em: http://www.mma.gov.br/biomas> /MMM. Acesso em: 12 de junho de 2016.

BARROS, L. G. V.; ALMEIDA, V. R. A contribuição da pesquisa empírica na análise da proteção jurídica do cerrado mineiro. Revista Meio Ambiente e Sustentabilidade, $\quad$ v.3 $\quad$ n.2, $2013 . \quad$ Disponível em: https://www.uninter.com/revistameioambiente/index.php/meioAmbiente/article/view/1 94

BORGES, V. C. O cerrado de "pé": potencialidades das plantas medicinais. Ateliê Geográfico, v. 7, n. 1, 2013, p.25-58. DOI: https://doi.org/10.5216/ag.v7i1.9224.

BRASIL, Ministério do Meio Ambiente. Plano de Ação para prevenção e controle do desmatamento e das queimadas: cerrado. Ministério do Meio Ambiente. Brasília: $\quad$ MMA, 2011. Disponível em: http://www.mma.gov.br/estruturas/201/_arquivos/ppcerrado_201.pdf.

PPCerrado - Plano de Ação para prevenção e controle do desmatamento e das queimadas no Cerrado: $2^{\text {a }}$ fase (2014-2015). Ministério do Meio Ambiente, Organizador. Brasília: MMA, 2014. Disponível em: http://combateaodesmatamento.mma.gov.br/images/conteudo/PPCerrado_2aFase.p df

Lei. Conselho Nacional do Meio Ambiente - CONAMA. 2016. Disponível em: <http://www.mma.gov.br/port/conama/legiano.cfm?codlegitipo=1>. Acesso em: 12 de junho de 2016. 
FERNANDES, P. A.; PESSÔA, V. L. S. O Cerrado e Suas Atividades Impactantes: Uma Leitura Sobre o Garimpo, a Mineração e a Agricultura Mecanizada. OBSERVATORIUM: Revista Eletrônica de Geografia, v.3, n.7, p. 19-37, 2011. Disponível em: http://www.observatorium.ig.ufu.br/pdfs/3edicao/n7/2.pdf.

FRANCISCO, W. C. Ação do fogo no cerrado. Brasil Escola. Disponível em $<$ http://brasilescola.uol.com.br/brasil/a-acao-fogo-no-cerrado.html/2016>. Acesso em 12 de dezembro de 2016.

G1, Portal Globo. Governo decreta situação de emergência por causa de queimadas. 16/10/2016b. Disponível em: <http://g1.globo.com/ma/maranhao/noticia/2016/10/governo-decreta-situacao-deemergencia-por-causa-de-queimadas.html>.

$\overline{09 / 12 / 2016 a \text {. }}$

. Maranhão é o $3^{\circ}$ em número de queimadas no país em 2016, diz Inpe. <http://g1.globo.com/ma/maranhao/noticia/2016/12/maranhao-e-o-3-em-numero-dequeimadas-no-pais-em-2016-diz-inpe.html>. Acessado em: 17 de setembro de 2016.

GASPAR, L. Queimadas no Brasil. Bibliotecária da Fundação Joaquim Nabuco, Recife, $2012 . \quad$ Disponível em: <http://basilio.fundaj.gov.br/pesquisaescolar/index.php?option=com content\&view=article\&id=890\&ltemid $>$. Acesso em: 30 de novembro de 2016.

GIL, A. C. Métodos e técnicas de pesquisa social. 6. ed - São Paulo: Atlas, 2009. IBGE, Instituto Brasileiro de Geografia e Estatística. Indicadores de desenvolvimento sustentável: Brasil: 2015/ IBGE. Coordenação de Recursos Naturais e Estudos Ambientais [e] Coordenação de Geografia. Rio de Janeiro: IBGE, 2015.2 Disponível em: https://biblioteca.ibge.gov.br/visualizacao/livros/liv94254.pdf.

INPE, Instituto de Pesquisas Espaciais. Mapa da área queimada. 2016a. disponível em: <https://prodwww-queimadas.dgi.inpe.br/aq1km/\#>. Acesso em: 13 de dezembro de 2016.

- Monitoramento dos focos ativos por estados. Programa de Queimadas do Instituto de Pesquisas Espaciais. Brasília: INPE, 2016b. Disponível em: $<$ http://www.inpe.br/queimadas/situacao-atuals. Acesso em: 13 de dezembro de 2016.

MARQUI, D. C. Queimadas e suas consequências. [monografia]. Universidade de São Paulo Instituto de Química de São Carlos. Programa de Educação Tutorial PET. São Carlos, 2011. Disponível em: http://pet.iqsc.usp.br/files/monografia.pdf.

NASCIMENTO, I. V. Cerrado: o fogo como agente ecológico. Territorium, v. 8, p. 25-35.

Disponível

em: https://www.uc.pt/fluc/nicif/riscos/Documentacao/Territorium/T08_artg/T08_artg03.pd 
f.

PEREIRA, B. A. S.; VENTUROLI, F.; CARVALHO, F. A. Florestas estacionais no cerrado: uma visão geral. Pesquisa Agropecuária Tropical, v. 41, n. 3, p. 446-455, 2011. Disponível em: https://www.revistas.ufg.br/pat/article/view/12666.

SILVEIRA, E.P. Florística e estrutura da vegetação de Cerrado sensu stricto em Terra Indígena no noroeste do estado de Mato Grosso. 2010. 61p. Dissertação (Mestrado em Ciências Florestais e Ambientais) - Universidade Federal de Mato Grosso, Cuiabá - $\quad$ MT, 2010. Disponível em: http://www.ufmt.br/ufmt/unidade/userfiles/publicacoes/2ba3e86e7725b04a02e9e92e c7dcb4e1.pdf. 